\title{
IMPORTANCE OF ISS AND RTS IN TRAUMA PATIENTS OF A TERTIARY REFERRAL CENTRE IN EASTERN INDIA
}

\author{
Shibaji Basu1, Dipankar Kundu², Pankaj Kumar Sarkar ${ }^{3}$ \\ ${ }^{1}$ RMO cum Clinical Tutor, Department of General Surgery, Nilratan Sircar Medical College. \\ ${ }^{2}$ Assistant Professor, Department of General Surgery, Nilratan Sircar Medical College. \\ ${ }^{3}$ Assistant Professor, Department of General Surgery, Medical College Hospital.
}

\begin{abstract}
BACKGROUND

Trauma represents the third cause of death after cardiovascular disease and malignancy. Also in India, road traffic accidents are one of the leading causes of death. Rapid evaluation of trauma severity, prediction of prognosis and mortality rate and probability of survival along with rapid treatment of patients is necessary. One of the useful instrument for this is ISS and RTS scoring systems. This study evaluated 100 multitrauma patients in a tertiary referral hospital in eastern India based on ISS and RTS and compared their effectiveness on outcome.
\end{abstract}

\section{MATERIALS AND METHODS}

This prospective observational study was carried out on 100 polytrauma patients admitted in Nilratan Sircar Medical College and Hospital over a span of 7 months from January 2013 to July 2013. During this period, patients' data were collected by clinical evaluation and they were followed till discharge or death. The statistical outcome was done using SPSS software.

\section{RESULTS}

The average age of patients was $37.6 \pm 23.5$ years where minimum and maximum age was 12 and 85 years. The most common involved group was $31-40$ years ( 13 men and 1 woman). $84 \%$ of patients ( 84 cases were male) and $16 \%$ were female (16 cases). The most common causes of trauma were road traffic accidents with $76 \%$ frequency (76 cases) and then fall from height with $12.0 \%$ frequency ( 12 cases). Road traffic accident had the highest frequency in both genders. Other causes of trauma were physical assaults with $6 \%$ frequency ( 6 cases) and gunshot injury $6 \%$ (6 cases). Also from 100 studied patients, 5 cases (5\%) had blunt trauma and 2 cases $(2 \%)$ had penetrating trauma. The penetrating trauma occurs in ages less than 50 years and was in the range of 30-50 years. The average RTS was $6.4 \pm 0.47$ for patients who recovered well and $5.7 \pm 0.57$ for patients who didn't survive. For ISS it was $33.7 \pm$ 1.9 , patients who were discharged; and $34.7 \pm 1.6$, those who couldn't survive. Overall mortality was $13 \%$ ( 13 cases). In this study, the trauma score based on RTS correlated better than ISS with the overall clinical outcome.

\section{CONCLUSION}

The RTS scoring system performed better than the ISS in predicting mortality and probability of survival and hence a better and accurate trauma score system.

\section{KEYWORDS}

Road Traffic Accident, Injury Severity Score, Revised Trauma Score.

HOW TO CITE THIS ARTICLE: Basu S, Kundu D, Sarkar PK. Importance of ISS and RTS in trauma patients of a tertiary referral centre in Eastern India. J. Evolution Med. Dent. Sci. 2016;5(101):7425-7428, DOI: 10.14260/jemds/2016/1681

\section{BACKGROUND}

Traumatic injury is defined as damage to the body caused by an exchange with environmental energy that is beyond the body's resilience.[1] Polytrauma is a major cause of morbidity and mortality in both developed and developing countries.[2] Trauma remains the leading cause of death and disability in children and young adults. The most common causes are road traffic accidents, fall from height, bullet injuries. ${ }^{[3]}$ India has the fourth highest rate of road accident in the world.[4]

Financial or Other, Competing Interest: None.

Submission 11-11-2016, Peer Review 06-12-2016,

Acceptance 12-12-2016, Published 19-12-2016.

Corresponding Author:

Dr. Pankaj Kumar Sarkar,

\#334/4,

Dr. M. N. Saha Road,

Dumdum,

Kolkata-700074.

E-mail: pankajkrsarkar15@gmail.com

DOI: $10.14260 /$ jemds/2016/1681
Trauma score systems translate the severity of injury into a number which help surgeons to have a common language of interpreting polytrauma patients. Quantitative characterisations of injury are essential for research and hence meaningful evaluation, treatment and outcomes. [5]

The Abbreviated Injury Scale (AIS) and the Comprehensive Research Injury Scale (CRIS) were derived from initial studies to grade and categorise anatomic injuries from automobile accidents in an epidemiologic fashion. The Injury Severity Score (ISS), which was derived from these scales, assigned a single value of overall injury severity that correlated with survival in the multiply injured blunt-trauma patient. The Anatomical Index (Al) was designed to more easily calculate probability of death from particular anatomic injury codes. The Trauma Score and Revised Trauma Score were physiologic assessments that used the clinical status of the patient in the field and emergency room to triage patients prior to full knowledge of the organs injured.

The RTS methodology offers a standard approach for tracking and evaluating outcome of trauma care. 
This study is being undertaken to compare RTS with ISS in predicting clinical outcome of polytrauma patients and thereby establishing itself as a better scoring system.

\section{MATERIALS AND METHODS}

One hundred consecutive cases of trauma of adult age group admitted in casualty of Nilratan Sircar Medical College and Hospital, Kolkata, from 1/1/2013 onwards included in the study.

\section{Exclusion Criteria}

1. Patients below the age of 12 years.

2. Burns.

The patients were attended at the ED (emergency department) and initially managed on ATLS protocol with simultaneously ISS \& RTS scoring. After stabilising the patient, detailed history was recorded and general physical/systemic examination was done. The following were determined:

1. RTS.

2. ISS

3. Associated injuries.

The revised trauma score is made up of a combination of results from three categories; Glasgow Coma Scale, Systolic blood pressure, and respiratory rate. The score ranges from 0 12.

\begin{tabular}{|c|c|c|c|}
\hline $\begin{array}{c}\text { Glasgow } \\
\text { Coma Score }\end{array}$ & SBP & RR & POINTS \\
\hline $15-13$ & $>89$ & $10-29$ & 4 \\
\hline $12-9$ & $76-89$ & $>29$ & 3 \\
\hline $8-6$ & $50-75$ & $6-9$ & 2 \\
\hline $5-4$ & $1-49$ & $1-5$ & 1 \\
\hline 3 & 0 & 0 & 0 \\
\hline Revised Trauma Score variables used for Scoring \\
\hline
\end{tabular}

\section{Weights for revised trauma score}

GCS - 0.9368 .

Systolic B.P - 0.7326.

Respiratory rate -0.2908 .

The sum of these three products is the revised trauma score (RTS).

$\mathrm{RTS}=0.9368(\mathrm{GCS})+0.7326(\mathrm{SBP})+0.2908(\mathrm{RR})$.

The injury severity score as calculated by abbreviated injury score (AIS) is a simple numerical method for grading and comparing injury by severity. The AIS is a consensus derived, anatomically based system of grading injuries on an ordinal scale ranging from 1 (minor injury) to 6 (Lethal injury).[6]

The ISS is defined as the sum of squares of the highest AIS grade in the 3 most severely injured body regions. Six body regions are defined as follows: The thorax, abdomen and visceral pelvis, head and neck, face, bony pelvis and extremities, and external structures. Only one injury per body region is allowed. The ISS ranges from 1-75, and an ISS of 75 is assigned to anyone with AIS of 6.

The performance of RTS, ISS as predictors of survival was evaluated from the information gained and by application of statistical analysis.

\section{RESULTS}

\section{Observations}

One hundred cases of trauma admitted through the Emergency Department of Nilratan Sircar Medical College and Hospital, Kolkata have been studied. The epidemiology of trauma, patient's characteristics, and their relation to mortality has been studied.

The average age of patients was $37.6 \pm 23.5$ years where minimum and maximum age was 12 and 85 years.

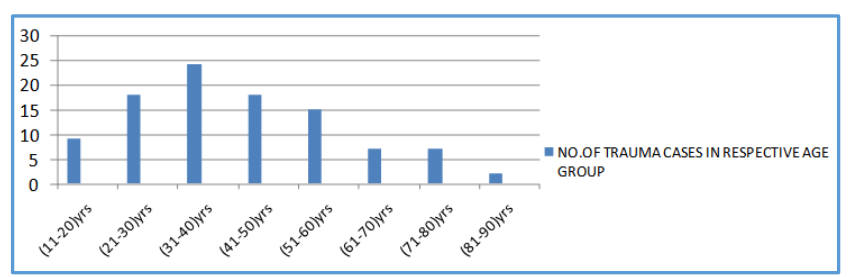

Figure 1. Frequency Distribution of Study Population according to Age Groups $(n=100)$

The most common involved group was $31-40$ years (13 men and 1 woman). $84 \%$ of patients ( 84 cases were male) and $16 \%$ were female (16 cases), thereby indicating male preponderance.

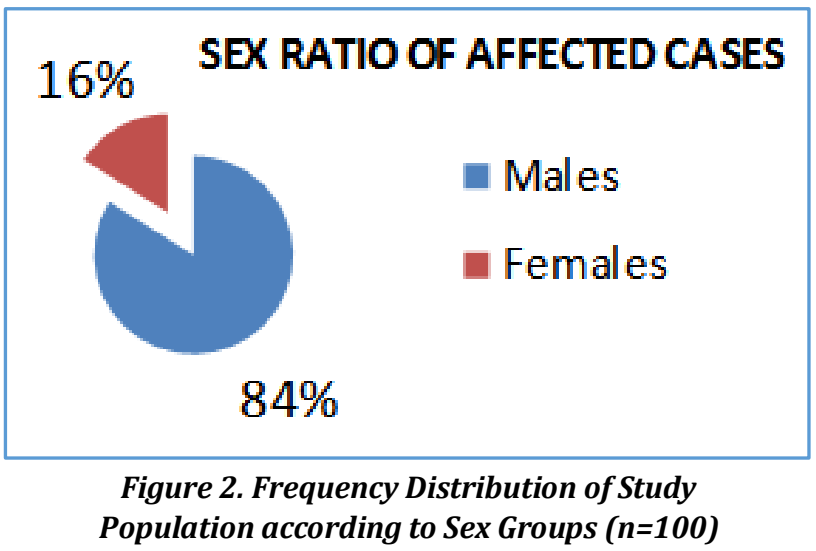

The most common causes of trauma were road traffic accidents with $76 \%$ frequency (76 cases) and then fall from height with $12.0 \%$ frequency ( 12 cases). Road traffic accident had the highest frequency in both genders. Other causes of trauma were physical assaults with $6 \%$ frequency ( 6 cases) and other miscellaneous injury $6 \%$ ( 6 cases).

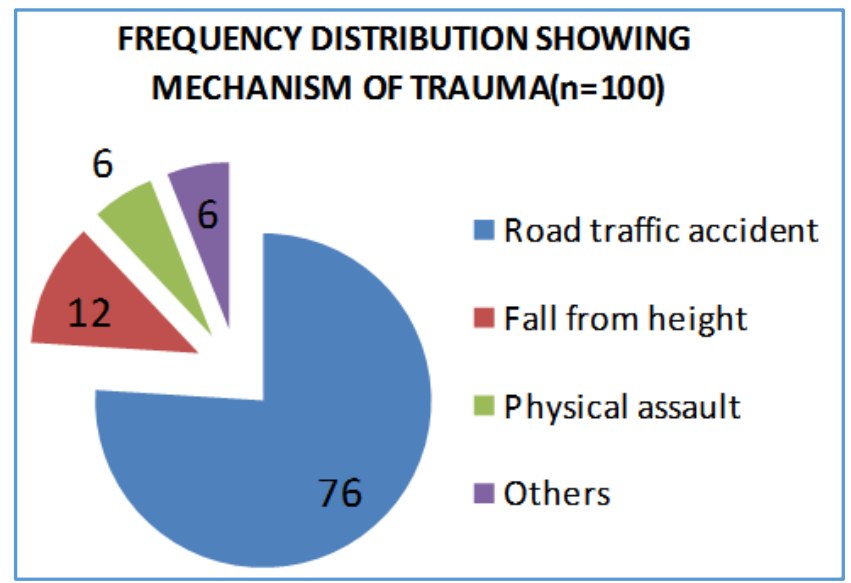

Figure 3. Mechanism of Trauma among 100 Cases 
$39 \%$ of patients arrived between 4-12 hours following injury, of which 3 patients succumbed to death. Of the $27 \%$ cases who arrived between 2 to 4 hours, 25 cases survived. $12 \%$ cases presented between 1-2 hours of trauma and $7 \%$ cases presented within an hour. There was death of only 2 cases, those presented within 2 hours. $15 \%$ cases presented after a delay of 12 hours and among them 6 cases died.

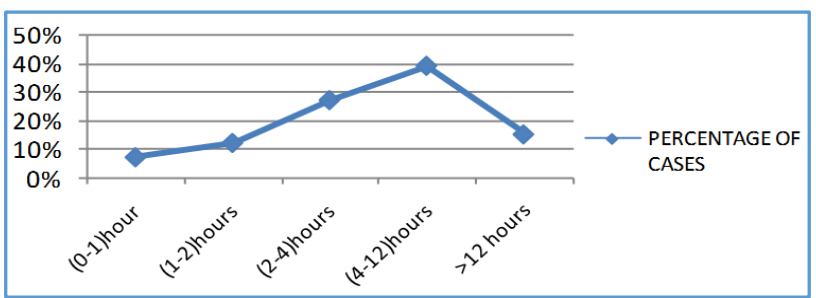

Figure 4. Time of Arrival

Region affected by injury: Head and neck was the most commonly injured region. Injuries of the head and neck region along with orthopaedic injuries constituted more than $76 \%$ of the total cases.

\section{DISTRIBUTION OF INJURY BY REGION}

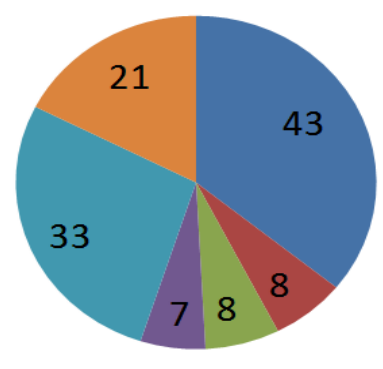

- Head and neck

Face

Thorax

Abdomen and pelvis

Limbs

External surface

Figure 5

Figure 5. Distribution of injury by region managed conservatively and the remaining 2 cases required laparotomy. All the 5 cases could be discharged under favourable condition. There were 2 cases of penetrating trauma of which one succumbed to death.

The ISS and RTS of the hundred cases were calculated. The average ISS for patients who went on to recover well was $33.7 \pm 1.9$ whereas for cases which couldn't survive was $34.7 \pm 1.6$. On the other hand, average RTS for patients doing well was $6.4 \pm 0.47$ and $5.7 \pm 0.57$ for cases not surviving. The correlation between trauma scoring and survival outcome establishes RTS as a better scoring system.

The overall mortality was $13 \%$ (13 cases). The age wise mortality chart is given below-

\begin{tabular}{|c|c|c|c|}
\hline Age Group (Years) & Total Cases & Expired & Alive \\
\hline$(11-20)$ & 9 & 0 & 9 \\
\hline$(21-30)$ & 18 & 1 & 17 \\
\hline$(31-40)$ & 24 & 1 & 23 \\
\hline$(41-50)$ & 18 & 1 & 17 \\
\hline$(51-60)$ & 15 & 4 & 11 \\
\hline$(61-70)$ & 7 & 3 & 4 \\
\hline$(71-80)$ & 7 & 2 & 5 \\
\hline$(81-90)$ & 2 & 1 & 1 \\
\hline \multicolumn{4}{|r}{ Figure 6. Age wise Mortality Chart } \\
\hline
\end{tabular}

\section{DISCUSSION}

The main use of trauma scoring systems has been to predict the need for expert surgical care of severely injured patients and to allow comparison of such patient care among hospitals. The main goal of most scoring systems has been to provide an estimated probability of death.

Evaluation of 100 cases of trauma to rate the severity of injury has been done. A physiologic RTS and an anatomic ISS index have been used for this purpose. The comparison between the two scoring systems has been done to assess their influence on survival.

Several Factors Useful in Studying the Epidemiology of Trauma Cases were also Studied

1. Age and Sex- It is a well-known fact that trauma principally affects the young population. ${ }^{[7-9]}$ In our study, $50 \%$ of the patients were between the age group $20-40$ years. There is a marked male preponderance in all communities of the world among trauma victims (WHO 1975). In our study, males comprised $83.7 \%$ of the patients. The results are comparable with another study done in India.[10]

2. Cause of Injury- In most of the studies on epidemiology of trauma, majority of the cases are due to road side collisions. ${ }^{[7-10]}$ Motor vehicles were responsible for $76.4 \%$ and $73.4 \%$ injuries in two Canadian centres. In our study, traffic collisions were responsible for $71 \%$ of cases.

3. Time of Arrival- The recognition of the fact that time lapse between the time of injury and start of definitive treatment is vital to the outcome has been recognised for a long time.[11] In our study, we found that there was a graded increase in mortality with increase in delay in arrival. In a developing country like India, trauma care centres are limited to big cities only and common man does not have easy access to these centres.

4. Region Affected by Injury- Head and neck accounted for $43.7 \%$ of injured patients followed by lower limb injuries (33.8\%). The findings are comparable to the results of other studies.[10,12]

5. Mortality- The analysis of affect of age on mortality in our study brought forward the fact that mortality increases with age, which was comparable to results by other studies. ${ }^{[7,8]}$ Copes et al (1988) in a large study showed that mortality becomes nearly double for patients over $50 \mathrm{yrs}$. of age for the same degree of injury severity as compared to patients below 50 yrs. of age. ${ }^{[13]}$ Champion et al (1990) also reported similar findings.

6. RTS and ISS Index- In our study, the outcome of the patients was compared based on the RTS and ISS values. It was found that physiologic variables in RTS scoring index found to be better predictors of survival compared to ISS.

7. Kalaycioglu et al in their study have found the scoring system to be a valuable tool for assessing the clinical outcome.[14,15]

\section{CONCLUSIONS}

Numerous scoring systems are available, each having its own shortcomings.[16] In this study, 100 trauma patients were evaluated using RTS and ISS methodology for the severity of injury and outcome.

The patient's age ranged from 12 years to 85 years with a male preponderance in 5.2:1 ratio. In $76 \%$ cases, the cause of 
trauma was road traffic accident followed by fall from height (12\%). Injury to head neck region combined with orthopaedic injuries made up to $76 \%$ of the injuries by region. It has been found that there was a delay in arriving to the hospital following trauma. $39 \%$ patients presented from 4 hours to 12 hours following trauma. The RTS ranged from 5.13 to 6.87 . There was a graded increase in mortality with decreasing RTS score. The ISS score ranged from 31.8 to 36.3 . The mortality increase didn't correlate with increasing ISS. Comparable performances of the RTS and ISS showed ISS as the poorer index than RTS

\section{REFERENCES}

1. Haddon W. Advances in the epidemiology of injuries as a basis for public policy. Public Health Rep 1980;95(5):41121.

2. Matar ZS. The clinical profile of poly trauma and management of abdominal trauma in a general hospital in the central region of the kingdom of Saudi Arabia. The Internet J Surg 2008;14:11.

3. Stewart RM, Myers JG, Dent DL, et al. Seven hundred fiftythree consecutive deaths in a level I trauma center: the argument for injury prevention. J Trauma 2003;54(1):6671.

4. Heyworth J, Shepherd J, Timoney N. Trauma services in a district general hospital. BMJ 1990;300(6728):876-7.

5. Baxt WG, Moody P. The differential survival of trauma patients. J Trauma 1987;27(6):602-6.

6. Sammour T, Kahokehr A, Caldwell S, et al. Venous glucose and arterial lactate as biochemical predictors of mortality in clinically severely injured trauma patients-a comparison with ISS and TRISS. Injury 2009;40(1):104-8.
7. Gennarelli TA, Wodzin E. AIS 2005: a contemporary injury scale. Injury 2006;37(12):1083-91.

8. Baker SP. Injuries: the neglected epidemic: stone lecture, 1985 American trauma society meeting. J Trauma 1987;27(4):343-8.

9. Agarwal ND. National policy on collisions. Indian J Orthop 1985;10:167-8.

10. Guirguis EM, Hong C, Liu D, et al. Trauma outcome analysis of 2 Canadian centers using the TRISS method. J Trauma 1990;30(4):426-9.

11. Murlidhar V, Roy N. Measuring trauma outcomes in India: an analysis based on TRISS methodology in a Mumbai university hospital. Injury 2004;35(4):386-90.

12. Oreskovichm MR, Carrico J. Trauma: management of the acutely injured patient. In: Sabiston DC. edr. Textbook of surgery. Vol. 1. Philadelphia: Igakushoin/Saunders 1986. p. 294.

13. Moylan JA, Detmer DE, Rose J, et al. Evaluation of the quality of hospital care for major trauma. J Trauma 1976;16(7):517-23.

14. Copes WS, Champion HR, Sacco WJ, et al. The injury severity score revisited. J Trauma 1988;28(1):69-77.

15. Kalaycioglu N, Yumru C, Cengiz N, et al. Comparison of the clinical judgment with SAPS II, ISS-RTS-TRISS, SOFA for prediction of outcome in ICU patients: A-736. Eur J Anaesthesiol 2006;23:191.

16. Herridge MS. Prognostication and intensive care unit outcome: the evolving role of scoring systems. Clin Chest Med 2003;24(4):751-62. 